\section{Prefrontal Lobotomy}

Nathan D. Zasler ${ }^{1}$ and Paul E. Kaplan ${ }^{2}$

${ }^{1}$ Concussion Care Centre of Virginia, Ltd., Richmond, VA, USA

${ }^{2}$ Capitol Clinical Neuroscience, Folsom, CA, USA

\section{Definition}

Prefrontal lobotomy is a neurosurgical procedure that used to be much more in evidence than it is at present. Prefrontal denotes the anterior component of the frontal lobe of the cerebral hemisphere and the granular frontal cortex. It is also anterior to the premotor area of the cerebral hemisphere. Long ago, it was thought that a bilateral removal of these areas of the cerebral hemispheres would lessen the antisocial activity potential in that treated patient and lower the capability for participation in violent crime. This procedure was thought to have a capacity to reduce the number of inpatient beds filled by psychiatric patients with violent histories. Postoperative psychiatric inpatients were actually augmented. Side effects and complications were significant enough that this neurological surgical procedure is not as frequently used and it is used only for very special indications.

\section{Current Knowledge}

The application of this neurological surgical procedure was previously much more common than at present. This procedure is now relatively rare.

\section{Cross-References}

Behavioral Assessment

- Leukotomy

- Lobotomy (Frontal)

$\checkmark$ Psychotherapy

\section{References and Readings}

http://www.alleydog.com/glossary/definition.php?term= Lobotomy\%20(Prefrontal\%20Lobotomy). Accessed 10/8/16.

Miller, B. L., \& Cummings, J. L. (1999). The human frontal lobes. New York: Guilford Press.

Stuss, D. T., \& Knight, R. T. (Eds.). (2002). Principles of frontal lobe function. New York: Oxford University Press. 